\title{
Capsule Commentary on Sentell et al., The Influence of Community and Individual Health Literacy on Self-Reported Health Status
}

\author{
Jennie A. Abrahamson, MBI, MLIS \\ Faculty of Information \& Media Studies, The University of Western Ontario, London, Ontario, Canada.
}

J Gen Intern Med 29(2):360

DOI: $10.1007 / \mathrm{s} 11606-013-2684-\mathrm{x}$

(c) Society of General Internal Medicine 2013

"N o man (or woman) is an island." 1 While we may instinctively accept this as citizens of a networked, globalized society, Sentell et al. provide empirical evidence of this truth as it relates to health literacy, and a novel approach to foster further work. ${ }^{2}$ Findings that individuals' poor self-rated health increases $2 \%$ for each percentage increase in community low health literacy are compelling. However, health literacy is complex. Another study recently found that poverty may directly affect peoples' ability to make "good" decisions, including those related to their health. ${ }^{3}$ This is something that improving health literacy is believed to help. We may find, though, that poverty and health literacy function independently as they relate to health decision-making and associated health outcomes. If so, efforts to improve health by increasing health literacy in economically challenged individual patients and communities may prove futile if we do not address their poverty directly.

Though Sentell et al. found that both low health literacy and low education levels relate significantly to poor health, other studies report that even individuals with high levels of education may not be health literate. We can help increase health literacy skills to support good self-care, but it is vital to better understand how and why some people use (or still don't use) health information and health services to improve their health. Central to making progress in this area is achieving a better understanding of causal pathways between health literacy and health outcomes, and the possible influences of other factors within the contexts in which people live and make health care decisions. ${ }^{4}$ Part of this effort, as the authors observe, should include further research to explore health literacy and health status in relation to individuals' local community: their families and social networks, including those virtual communities fostered by internet and communication technologies. It is within all these communities that people "live" their health care decisions, and where everyday health outcomes are ultimately "made." Then we can develop targeted clinical and public health interventions and policies that more effectively improve individual and community health outcomes.

Conflict of Interest: The author has no conflicts of interest with the material in this article.

Corresponding Author: Jennie A. Abrahamson, MBI, MLIS; Faculty of Information \& Media Studies, The University of Western Ontario, London, Ontario N6A 5B7, Canada (e-mail:jabraha9@uwo.ca).

\section{REFERENCES}

1. Donne J. "Meditation XVII" in Devotions Upon Emergent Occasions; Together with Death's Duel. 1959. Ann Arbor: University of Michigan Press.

2. Sentell T, Zhang W, Davis J, Kromer KB, Braun KL. The influence of community and individual health literacy on self-reported health status. J Gen Intern Med. 2013; doi:10.1007/s11606-013-2638-3.

3. Mani A, Mullainathan S, Shafir E, Zhao J. Poverty impedes cognitive function. Science. 2013; 341(976):976-80.

4. Paasche-Orlow MK, Wolf MS. The causal pathways linking health literacy to health outcomes. Am J Health Behav. 2007;31(Suppl 1):S19-26.

5. Abrahamson JA, Fisher KE, Turner AG, Durrance JC, Turner TC. Lay information mediary behavior uncovered: exploring how nonprofessionals seek health information for themselves and others. J Med Libr Assoc. 2008;96(4)310-23. doi:10.3163/1536-5050.96.4.006. 